\title{
PENYULUHAN DAN PERUBAHAN PENGETAHUAN CUCI TANGAN PAKAI SABUN DI DESA SUKOWIDI KABUPATEN MAGETAN
}

\author{
Avicena Sakufa Marsanti \\ Program Studi Kesehatan Masyarakat STIKES Bhakti Husada Mulia Madiun
}

\begin{abstract}
Data from primary health care Panekan showed that incidence of diarrhea was increased. The Cause of Diarrhea is a wrong Hand washing Practice. Based on interview over the last 6 month, 10 people didn't know the importance of hand washing. The objective of this study was to determine This study was experimental one group pretest and postest design with 100 family for samples and proportionate random sampling technique. This study was analyzed by paired t-test with significance $\mathrm{P}>0.05$. The result showed that there was an effect between counseling and knowledge about hand washing with soap $(\mathrm{p}<0,001)$. Before the counseling, the mean of knowledge score was $63,6 \pm 7,91$ and after counseling was $79,90 \pm 7,25$. There was an effect of counseling and changes in knowledge about hand washing with soap in Sukowidi, Magetan, the mean of knowledge score was better after counseling.
\end{abstract}

\section{Keywords: Counseling, knowledge, hand washing with soap}

\section{PENDAHULUAN}

Cuci tangan dianggap merupakan salah satu langkah yang paling penting untuk mengurangi penularan mikroorganisme dan mencegah infeksi selama lebih dari 150 tahun. Kesehatan dan kebersihan tangan yang baik dapat mencegah penularan mikroorganisme dan mengurangi frekuensi infeksi nosokomial. Walaupun demikian, masalah yang timbul terus menerus adalah memungkinkan para petugas kesehatan untuk menjalankan praktik cuci tangan yang dianjurkan. Misalnya, di US tingkat kepatuhan cuci tangan diantara para petugas kesehatan mempunyai kisaran dari $25 \%$ hingga $50 \%$, tergantung pada unit atau tempat (misalnya, kepatuhan lebih baik pada unit kesehatan anak daripada unit layanan (kesehatan umum) (Tietjen, 2004: 3 - 10). Indeks pembangunan kesehatan masyarakat Jawa Timur (IPKM) 2010 menunjukkan, prosentase rumah tangga yang memenuhi kriteria untuk cuci tangan hanya sebesar 27,35\%. Warga di Kabupaten Magetan biasa mencuci tangan di kamar mandi dan tempat cuci piring serta di dapur. Sebagian besar anggota keluarga responden mencuci tangan setelah makan yaitu $74,4 \%$, setelah buang air besar $73,9 \%$, sebelum makan $69,6 \%$. Sedangkan cuci tangan setelah menyeboki anak, sebelum menyiapkan masakan dan sebelum menyuapi anak prosentasenya lebih sedikit.

Tangan merupakan salah satu jalur utama masuknya kuman penyakit ke dalam tubuh. Hal tersebut dikarenakan tangan adalah anggota tubuh yang paling sering berhubungan langsung dengan mulut dan hidung. Penyakitpenyakit yang umumnya timbul karena tangan yang berkuman, antara lain: diare, kolera, ISPA, cacingan, flu dan hepatitis A (Proverawati, 2012: 72). Oleh karena itu, dilakukan penelitian untuk membuktikan pengaruh pemberian penyuluhan terhadap pengetahuan responden mengenai cuci tangan pakai sabun (CTPS).

\section{METODE PENELITIAN \\ Jenis Penelitian}

Desain penelitian yang digunakan peneliti adalah experimental one group pre test post test.

\section{Instrumen Penelitian}

Instrumen yang dipakai dalam penelitian ini adalah tes pengetahuan CTPS yang meliputi definisi cuci tangan, tujuan cuci tangan, alat dan bahan cuci tangan, manfaat cuci tangan, cara mencuci tangan, dan peran kader dalam membina.

\section{Waktu dan Tempat Penelitian}

Penelitian ini dilakukan pada bulan Agustus September 2015 di Desa Sukowidi RW 01 Kecamatan Panekan Kabupaten Magetan.

\section{Populasi dan Sampel}

Pada penelitian ini populasi yang akan digunakan adalah seluruh Kepala Keluarga 
(KK) Rukun Warga (RW) 01 Desa Sukowidi Kecamatan Panekan Kabupaten Magetan yang berjumlah $141 \mathrm{KK}$.

Besar sampel yang digunakan adalah 100 kepala keluarga dengan metode pengambilan sampel proportionate random sampling. Sebelum diberikan perlakuan (penyuluhan) responden diberikan pre test. Setelah diberikan penyuluhan, responden diberikan post test.

\author{
Analisis Data \\ Data dianalisis dengan Paired T-Test.
}

\section{HASIL PENELITIAN}

Hampir setengah dari responden $(42 \%)$ berusia 27 - 37 tahun dan sebagian kecil responden (13\%) berusia $16-26$ tahun. Sebagian besar responden (40\%) tamat SMP dan hanya 6\% yang memiliki pendidikan tamat perguruan tinggi.

Tabel 1. Karakteristik Responden di Desa Sukowidi Kabupaten Magetan

\begin{tabular}{lccc}
\hline No. & Variabel & Frekuensi & Persentase \\
\hline 1. & Umur (tahun) & & \\
& $16-26$ & 13 & 13,0 \\
$27-37$ & 42 & 42,0 \\
& $38-48$ & 30 & 30,0 \\
& $49-59$ & 15 & 15,0 \\
2. Tingkat Pendidikan & 32 & 32,0 \\
& SD & 40 & 40,0 \\
& SMP & 22 & 22,0 \\
& SMA & 6 & 6,0 \\
\hline
\end{tabular}

Berdasarkan hasil pre dan post test, terdapat perbedaan rata-rata skor dan nilai minimal maupun maksimal, yaitu lebih tinggi setelah penyuluhan dibandingkan sebelum penyuluhan.

Tabel 2. Pengetahuan Responden di Desa Sukowidi Kabupaten Magetan

\begin{tabular}{lccc}
\hline \multicolumn{1}{c}{ Variabel } & Mean \pm SD & Min & Max \\
\hline Pengetahuan & & & \\
Sebelum Penyuluhan & $63,65 \pm 7,91$ & 45 & 80 \\
Setelah Penyuluhan & $79,90 \pm 7,25$ & 50 & 100 \\
\hline
\end{tabular}

Berdasarkan analisis bivariat menggunakan uji $\mathrm{T}$ berpasangan, ada pengaruh pemberian penyuluhan dengan pengetahuan tentang CTPS pada responden $(\mathrm{p}<0,001)$.

Tabel 3. Hasil Uji Statistik Pengetahuan Responden Sebelum dan Setelah Penyuluhan di Desa Sukowidi Kabupaten Magetan

\begin{tabular}{cccc}
\hline Pengetahuan & Mean \pm SD & R & p \\
\hline Sebelum-Setelah & $16,25 \pm 5,09$ & 0,777 & $<0,001$ \\
\hline
\end{tabular}

\section{PEMBAHASAN}

Nilai rata-rata tingkat pengetahuan responden lebih besar setelah dilakukan penyuluhan CTPS, dibandingkan sebelum penyuluhan. Setelah dianalisis secara bivariat, terdapat pengaruh antara pengetahuan sebelum dan setelah dilakukan penyuluhan CTPS karena memiliki nilai $\mathrm{p}<0,05$. Peningkatan pengetahuan masyarakat setelah diberi penyuluhan karena masyarakat telah mengalami 
proses untuk mengetahui sesuatu. Masyarakat mendapatkan informasi sehingga dapat memahaminya (Potter dan Perry, 2005).

Hasil penelitian ini sejalan dengan penelitian yang dilakukan Dyna Apriany (2012) menunjukkan rata-rata pengetahuan mencuci tangan responden yang ada di TK At-Taqwa Cibeber Cimahi pada pengukuran pertama (pre test) adalah 2,78 dengan standar deviasi 0,420. Sedangkan pada pengukuran kedua (post test) didapat rata-rata pengetahuan mencuci tangan responden adalah 9,44 dengan standar deviasi 1,162. Hasil uji statistik didapatkan nilai $\mathrm{p}$ value untuk uji dua sisi (2-tailed) $0,0001 \leq \alpha$ $(0,05)$, maka dapat disimpulkan terdapat pengaruh yang signifikan antara pengetahuan mencuci tangan sebelum dan sesudah diberikan pendidikan kesehatan.

Penelitian lain yang dilakukan pada siswa SD Negeri 157 Kota Palembang juga menunjukkan hasil yang sama, yaitu ada pengaruh pemberian pendidikan kesehatan terhadap tingkat pengetahuan siswa $(\mathrm{p}=0,012)$ (Nikson Sitorus, 2014). Hasil penelitian ini sejalan dengan penelitian lain yang menunjukkan peningkatan pengetahuan siswa SD Inpres Baraya 1 Kota Makassar $(p=0,002)$ (Sumarmi, 2013).

Hal tersebut sesuai dengan teori Notoatmodjo (2007), pendidikan merupakan salah satu faktor internal yang mempengaruhi pengetahuan. Sedangkan menurut Nursalam (2003), pendidikan dapat mempengaruhi seseorang termasuk juga perilaku seseorang akal pola hidup terutama memotivasi untuk sikap berperan serta dalam pembangunan pada umumnya makin tinggi pendidikan seseorang makin mudah menerima informasi.

Melihat hasil penelitian model pemberian penyuluhan dan praktek CTPS lebih efektif untuk meningkatkan pengetahuan dengan harapan kedepannya mampu terjadi perubahan perilaku tentang CTPS setiap selesai makan, BAB, menceboki anak dan sebagainya yang akan mampu membantu menurunkan angka kejadian diare dan penyakit menular. Adanya pengetahuan responden yang bertambah mengenai CTPS, diharapkan pihak Desa ikut mendukung agar responden juga mau menerapkan cuci tangan dalam kehidupan sehari-hari, sehingga responden mampu menerapkan CTPS, dalam sikap sehari-hari dan meningkatkan derajat kesehatan responden RW 01 Desa Sukowidi.

\section{KESIMPULAN DAN SARAN}

Ada Pengaruh pemberian penyuluhan terhadap perubahan pengetahuan tentang cuci tangan pakai sabun di RW 01 di Desa Sukowidi Kecamatan Panekan Kabupaten Magetan.

Sebaiknya dilakukan penyuluhan secara rutin tentang CTPS dalam kegiatan warga, misalnya arisan, PKK atau kegiatan lain. Agama juga mengajarkan CTPS, yaitu kebersihan sebagian dari iman sehingga peyuluhan juga dapat dilakukan dalam kegiatan pengajian.

\section{DAFTAR PUSTAKA}

Dyna, Apriyani. (2012). Perbedaan Perilaku Mencuci Tangan Sebelum dan Sesudah Diberikan Pendidikan Kesehatan Pada Anak Usia 4 - 5 Tahun. Jurnal Keperawatan Soedirman. 7(2): 60-66.

Sitorus, Nikson, Luci Fransisca. (2014). Pengaruh Pendidikan Kesehatan

Terhadap Pengetahuan dan Sikap Cuci Tangan Pakai Sabun Pada Siswa SD Negeri 157 Kota Palembang Tahun 2014. Jurnal Poltekkes Palembang. 1-6.

Nursalam. (2003). Konsep dan Penerapan Metodologi Penelitian Ilmu Keperawatan Pedoman Skripsi, Tesis dan Instrumen Penelitian Keperawatan. Jakarta: Salemba Medika.

Potter dan Perry. (2005). Buku Ajar Fundamental Keperawatan. Jakarta: EGC.

Proverawati, R. (2012). Perilaku Hidup Bersih dan Sehat. Yogyakarta: Nuha Medika.

Sumarmi. (2013). Pengaruh Penyuluhan Kesehatan Terhadap Tingkat Pengetahuan dan Perilaku Cuci Tangan yang Benar Pada Siswa SD Inpres Baraya 1 Kota Makassar 2013. STIKES Tanawali Persada.

Tietjen. (2004). Panduan Pencegahan Infeksi. Jakarta: Yayasan Bina Pustaka Sarwono Prawirohardjo. 